\section{A NOVA RAZÃO DO MUNDO: ensaio sobre a sociedade neoliberal}

\author{
Felipe Queiroz *
}

Publicado originalmente na França em 2009, logo após a eclosão da crise financeira global, A nova razão do mundo: ensaio sobre a sociedade neoliberal (Dardot; Laval, 2016) apresenta uma profunda análise do neoliberalismo, mostrando como ele constitui, muito além de uma doutrina econômica ou ideologia, uma nova racionalidade de mundo, que estrutura e organiza tanto as ações dos governantes como a própria conduta dos governados. A obra faz uma genealogia do neoliberalismo para mostrar, por um lado, que ele não é uma simples continuidade do liberalismo clássico do século XVIII, do mesmo modo que não é seu extravio nem sua negação, e, por outro lado, para problematizá-lo a partir de suas vertentes e disputas internas, mostrando como ele passou de uma doutrina econômica para um "sistema normativo que ampliou sua influência ao mundo inteiro, estendendo a lógica do capital a todas as relações sociais e a todas as esferas da vida" (Dardot; Laval, 2016, p. 7). Nesse sentido, a obra busca fornecer subsídios à crítica ao neoliberalismo, na medida em que desfaz consensos e equívocos em torno dele.

A nova razão do mundo é o segundo livro publicado em conjunto pelos autores e resulta das investigações desenvolvidas no grupo de estudos e pesquisa que coordenam Question Marx. O primeiro livro derivado dos seminários Question Marx, Sauver Marx? Empire, multitude, travail immatériel (2007), faz uma crítica ao pensamento de alguns pós-marxistas, entre eles Michael Hardt e Antonio Negri, que entendem ser a autossuperação do capitalismo o resultado de suas próprias contradições internas e acatam a crença progressista segundo a qual todo passo dado pelo capitalismo é um avanço em direção ao momento de sua autossuperação. A nova razão do mundo se apresenta como continuidade dessa investigação, apontando como e porque "ainda não terminamos com o neoliberalismo”, quando muitos autores, no ápice da crise financeira internacional, como Joseph Stiglitz, anunciavam seu fim.

O livro está dividido basicamente em duas grandes partes: A refundação intelectual e A nova racionalidade. A primeira parte é, em certo sentido, uma tentativa de retomar o debate aberto por Michel Foucault nos cursos do Collège de France de 1977-1978 e 1978-1979, expostos respectivamente nos livros Segurança, Território, População e $O$ nascimento da biopolítica, apontando como se forma o neoliberalismo, como nova racionalidade do capitalismo contemporâneo. O ponto de partida da investigação dos autores é a crise do liberalismo, ou crise da governamentalidade liberal, nos termos de Michel Foucault, que dura entre 1880 e 1930. O objetivo é mostrar que o neoliberalismo não é uma simples continuidade das ideias liberais, mas, antes, marca um rompimento com a versão dogmática do liberalismo, que via no laissez-faire uma verdade inalienável. Enquanto o liberalismo clássico passava por uma profunda crise, a Revolução Russa, o avanço do socialismo e a disseminação das ideias de esquerda por toda Europa ameaçavam os liberais, impondo-lhes a necessidade de reformulação teórica do liberalismo. É nessa conjuntura de crise política, econômica e teórica que surge a principal tentativa de refundação do liberalismo: o Colóquio Walter Lippmann, em 1938. A partir do Colóquio, duas grandes correntes de pensamento neoliberal surgirão: a corrente austro-americana, representada por Friedrich A. Hayek e Ludwig von Mises, e a corrente ordoliberal alemã, cujos principais expoentes foram Walter Eucken e Wilhelm Röpke. 
O objetivo dessa parte não é fazer uma interpretação original do neoliberalismo, mas apontar as contribuições do pensamento dos principais teóricos neoliberais, especialmente os presentes no Colóquio de Walter Lippmann, para a instauração de uma nova racionalidade a partir da implantação dos governos neoliberais da década de 1970, especialmente o de Margareth Thatcher, na Inglaterra, e o de Ronald Reagan, nos Estados Unidos. Essa releitura do neoliberalismo a partir das lentes foucaultianas é, por um lado, a contribuição de Dardot e Laval ao debate teórico do neoliberalismo, e, por outro, elemento que une as duas partes de A nova razão do mundo. Os próprios autores reconhecem que a "racionalidade neoliberal que realmente se desenvolve nos anos 1980-1990 não é a simples implementação da doutrina elaborada nos anos 1930", numa espécie de passagem de "teoria para a prática". Antes, é o resultado de uma "multiplicidade de processos heterogêneos" que resultam nisso que os autores denominam de "nova racionalidade governamental" (Dardot; Laval, 2016, p. 33-34).

A segunda parte do livro A nova racionalidade analisará o neoliberalismo como razão do capitalismo contemporâneo. Na análise $\infty$ dos autores, a construção dessa nova racionaลे lidade governamental não é o resultado de um processo previamente orquestrado por uma classe ou "elite do poder", mas a confluência de uma "multiplicidade de processos heterogêneos"; nos termos foucaultianos, trata-se de uma "articulação estratégica”, numa espécie $\dot{i}$ de "estratégia sem sujeito". Apesar de ressal$\infty$
A problemática central de A nova razão do mundo é como a racionalidade neoliberal, baseada na concorrência integral em todos os âmbitos, adquire uma dimensão totalizadora, da qual nada escapa, abarcando desde o Estado até todas as esferas da existência humana. A construção dessa nova racionalidade, ou razão-mundo, nos termos dos autores, segue basicamente estes passos: "Da construção do mercado à concorrência como norma dessa construção, da concorrência como norma da atividade dos agentes econômicos à concorrência como norma da construção do Estado e de sua ação e, por fim, da concorrência como norma do Estado-empresa à concorrência como norma da conduta do sujeito-empresa" (Idem, p. 379).

Não há como compreender a razão neoliberal sem analisar primeiramente as mudanças ocorridas na própria concepção de Estado, entre as décadas de 1960 e 1980. O discurso contra o intervencionismo estatal ganhou o centro do debate especialmente após a década de 1970, quando se iniciam os governos neoliberais de Donald Reagan, nos Estados Unidos, e Margareth Thatcher, na Inglaterra. Apesar de haver um forte e contínuo discurso contra o Estado, na realidade, o neoliberalismo nunca vislumbrou o seu fim, mas sua transformação (Idem, p. 272-274).

A mudança na concepção e na ação do Estado apresentou-se por meio de sua reestruturação externa - privatizações das empresas públicas - e interna - o Estado passou a ser um avaliador e regulador que "mobiliza novos instrumentos de poder e, com eles, estruturas novas relações entre governo e sujeitos sociais" -, bem como a partir das mudanças lexicais no vocabulário político (Idem, p. 273-285). Para citar um exemplo amplamente analisado pelos autores, o termo governança tornou-se uma palavra-chave no vocabulário neoliberal. Segundo eles, o termo, dentro do arcabouço neoliberal, abarca três dimensões que estão cada vez mais entrelaçadas: a condução das empresas, a condução dos Estados e, por fim, a 
condução do mundo. No âmbito político, a palavra governança, passou a substituir a palavra soberania. Essa mudança é importante de ser notada, pois resultará não apenas em mudanças não apenas na relação interna do Estado, isto é, dentro de seu território e com sua população, mas na esfera internacional, geopolítica e geoeconômica.

$\mathrm{Na}$ fase do capitalismo neoliberal, os Estados passam a ser guiados pela lógica empresarial da concorrência. Desse modo, a concorrência entra em outro patamar: os países passam a concorrer globalmente pelos capitais estrangeiros, e os grandes oligopólios internacionais exercem grande influência nessa disputa. A concorrência entre os países na atração de investimentos externos faz com que legislações sejam revistas, acordo entre sindicatos e empresas revogados. Nesse sentido, duas mudanças devem ser notadas: a primeira diz respeito à relativização do papel do Estado como entidade integradora de todas as dimensões da vida coletiva. A segunda mudança deriva da primeira: todas as dimensões do Estado passam a ser geridas pela ótica da concorrência. Ou seja, o Estado passa a ser mais uma entidade que busca maximizar seus resultados, como uma empresa.

Nessa perspectiva, o Estado não é considerado uma entidade "exógena" à ordem do mercado, mas uma entidade totalmente integrada ao espaço e às leis das trocas, isto é, o Estado é mais uma empresa que está em concorrência no mercado global. Por isso, a reforma dos aparelhos do Estado é apresentada como um processo "neutro", "ideologicamente isento", com vistas apenas a critérios "técnicos". Esse discurso, que surgiu no seio da direita neoliberal norte-americana e inglesa, durante os governos de Reagan e Thatcher, será adotado pela socialdemocracia e pela esquerda europeia, na década de 1990 em diante. Um dos pontos altos do livro é mostrar como a social democracia e a esquerda europeia, em última instância, defenderam com grande vigor o programa neoliberal, sob o verniz da "moderniza- ção" do Estado. Os governos de Blair, Zapatero, Schröder e Hollande dão demonstração clara de que a "terceira via", nada mais é do que a "via neoliberal".

Essas mudanças na dimensão do Estado terão como consequência a perda do próprio significado dos serviços públicos, influenciando, consequentemente, a própria ideia de sujeito político. Em última instância, o que está em jogo é a própria dimensão do que é política, uma vez que a esfera do coletivo e do bem comum é preterida em favor do consumo egoísta imediato.

Não é apenas o Estado que se adequa a essa nova racionalidade neoliberal, mas toda a sociedade passa a ser concebida como um "mercado", no qual cada sujeito é uma "empresa” que está em contínua concorrência. Essa nova racionalidade passa a ser a mediadora de todas as relações sociais: "o homem neoliberal é o homem competitivo, inteiramente imerso na competição mundial” (Idem, p. 322). A competição introjeta-se até na esfera da subjetividade dos indivíduos. A vida passa a ser vista como uma empresa - um capital a ser continuamente valorizado -, na qual o indivíduo é empreendedor de si mesmo. É interessante notar como, para analisar o sujeito neoliberal ou neossujeito, os autores articulam os conceitos foucaultianos de governamentalidade, estratégia e dispositivo de poder com a teoria do valor de Marx.

Para Dardot e Laval, o neossujeito deve sempre "naturalizar" as regras do jogo neoliberal, isto é, se adaptar à nova realidade do Estado-empresarial - na qual previdência, saúde, educação e lazer são produtos que os consumidores (cidadãos) têm a "liberdade de escolher" e adquirir - e conviver com o desemprego permanente, a precarização das relações de produção e das relações sociais de produção. A naturalização do risco, a responsabilização individual pelas consequências de suas escolhas e a transformação dos indivíduos em sujeitos empreendedores de si, que estão em contínua competição e concorrência com os 
demais sujeitos empreendedores, são facetas dessa nova razão-mundo. Em contrapartida, essa mesma razão-mundo exige que o sujeito neoliberal se supere continuamente, seja flexível para acompanhar as mudanças impostas pelo mercado, se adapte às contínuas variações da demanda do mercado e assuma sempre os riscos. A naturalização da lógica dos realities shows (com a eliminação dos mais fracos e inaptos) e a "uberização" das relações de trabalho, com a "flexibilização" dos "colaboradores", são exemplos seminais dessa nova razão-mundo.

Contudo, a impossibilidade de governar um "mundo que se tornou ingovernável, em virtude de seu próprio caráter global”, e a infinita responsabilização dos indivíduos por seu próprio destino, sempre atendendo ao imperativo (inalcançável) de ser "bem-sucedido e feliz”, produzem uma sociedade esquizofrênica e doentia (Dardot; Laval, 2016, p. 344).

Dardot e Laval iniciam A nova razão do mundo discutindo que a crise financeira global não anunciava o fim do neoliberalismo, e terminam apontando que o neoliberalismo se tornou hoje a racionalidade dominante, e, por esse motivo, não será a crise que anunciará seu fim, uma vez que essa racionalidade "tomou corpo num conjunto de dispositivos dis$\infty$ Curs cursivos, institucionais, políticos, jurídicos e econômicos que formam uma rede complexa e movediça, sujeita a retomadas e ajustes em função do surgimento de efeitos não desejados, às vezes contraditórios com o que se buscava inicialmente" (Idem, p. 384). A nova razão do mundo é uma tentativa bem sucedida de mos$\dot{i}$ trar que essa razão neoliberal não se restringe apenas à esfera econômica, mas atravessa e envolve todas as dimensões da vida humana.

O diagnóstico dos autores conduz, inevitavelmente, a um pessimismo frankfurtiano, no qual não há uma saída viável no horizonte. Apesar de os autores afirmarem que $A$ nova razão do mundo "não cede lugar a nenhum fatalismo", antes procura "explorar formas inéditas de subjetivação que possibilitem co- locar em xeque o poder da razão neoliberal” (Idem, p. 290-291), apenas nas últimas páginas do livro são apresentados alguns pontos que podem indicar a construção de "outra razão de mundo", que surgirá a partir da construção da razão do comum, em contraposição à razão neoliberal. Na realidade, não fica claro como pode se dar a construção dessa nova razão do comum a partir dessas (não especificadas) "formas inéditas de subjetivação", uma vez que, ao longo do livro, especialmente na segunda parte, a argumentação é de que a racionalidade neoliberal é global e totalizadora, não possibilitando a construção de tipo algum de subjetividade para além dela.

Nesse sentido, entendemos ser possível fazer ao menos duas possíveis leituras das conclusões de Dardot e Laval. A primeira, mais pessimista, compreende a nova razão neoliberal como uma situação aporética, que os indivíduos não conseguem romper, nem construir novas formas de subjetivação. Essa leitura pode conduzir, em última instância, a uma (não) saída niilista, na qual, após terem sido sufocadas todas as tentativas de construção de subjetividades alternativas, os indivíduos resignam-se diante da inescapável situação dessa razão-mundo, por um lado. Ou, por outro lado, empreendem uma luta quixotesca e incansável contra essa racionalidade, recusando-se - por não conseguir se adaptar ou por escolha - a aceitar essa "jaula de aço" neoliberal. Esse é o dilema que o diretor Ken Loach retrata no filme $E u$, Daniel Blake.

A segunda leitura, essa defendida pelos autores, retomará alguns conceitos desenvolvidos por Foucault em Hermenêutica do sujeito e História da sexualidade, para argumentar que "o sujeito está sempre por construir", e que a aparente aporia do neoliberalismo traz consigo a construção de novas subjetividades, não baseadas no cálculo individual e egoísta, mas voltadas para a construção do comum. Desse modo, a análise de A nova razão do mundo deve ser feita dentro de uma construção teórica de Dardot e Laval. Ou seja, as alternativas 
ao sombrio diagnóstico feito nesse texto serão apresentadas nas duas publicações seguintes: Marx, prénom: Karl (2012) e Commun: essai sur la révolution au XXIe siècle (2014).

\section{REFERÊNCIAS}

DARDOT, Pierre; LAVAL, Christian. A nova razão do mundo: ensaio sobre a sociedade neoliberal. São Paulo: Editora Boitempo, 402 p, 2016.

Recebido para publicação em 26 de agosto de 2017 Aceito em 12 de janeiro de 2018

*Felipe Queiroz - Doutorando em Ciência Política na Unicamp. É Pesquisador do Centro de Estudos Marxistas (Cemarx) e editor da revista Cadernos Cemarx. Universidade Estadual de Campinas - Unicamp, IFCH- PPGCP. Rua Cora Coralina, 100 - Cidade Universitária Zeferino Vaz, Barão Geraldo. Campinas São Paulo - Brasil. felipequeiroz_braga@hotmail.com

\section{1}


